\title{
The influence of defects and conductivity on the domain structure properties and the memory effect in the ferroelectrics-semiconductors $\mathbf{S n}_{2} \mathbf{P}_{2} \mathbf{S e}_{6}$
}

\author{
Yu.M.Vysochanskii, A.A.Molnar, M.M.Khoma, S.F.Motrja \\ Institute of Solid State Physics and Chemistry Uzhgorod University, \\ 46 Pidgirna Str., 294000 Uzhgorod, Ukraine
}

Received July 6, 1998

For the proper uniaxial ferroelectrics $\mathrm{Sn}_{2} \mathrm{P}_{2} \mathrm{Se}_{6}$ with the controlled content of different type of impurities the investigations of dielectric permeability temperature dependence are performed with the aim to determine the influence of the crystal structure defects upon: the efficiency of the thermal memory effect recording in the incommensurate (IC) phase; the second order phase transition (PT) from the paraelectric phase to the IC phase at temperature $\mathrm{T}_{i}$ and upon the first order PT from IC phase to ferroelectric phase at temperature $T_{c}$; the anomalous hysteresis of the dielectric properties temperature dependence in the IC phase; the dielectric contribution of the domain walls in the ferroelectric phase. Static defects smear the anomaly at the PT from paraelectric phase to IC phase, increase the anomalous hysteresis in the IC phase and the hysteresis of the lock-in transition temperature $T_{c}$, suppress the dielectric contribution of domain walls in the ferroelectric phase and destroy the memory effect in the IC phase. The increase of the charge carrier concentration also suppresses the dielectric output of the domain walls in the ferroelectric phase but at the same time it supports a more clear memory recording in the IC phase. Such a tendency agrees with the estimations in the mean-field approximation for the characteristics of a domain structure in the ferroelectric phase and memory effect in the IC phase in the ferroelectrics-semiconductors investigated.

Key words: domain structure, ferroelectrics-semiconductors, influence of defects

PACS: $64.70 . R h, 67.70 . K b, 64.60 . F r$

\section{Introduction}

Interesting relaxation phenomena are observed [1] for the proper ferroelectricssemiconductors $\mathrm{Sn}_{2} \mathrm{P}_{2} \mathrm{~S}_{6}$ and $\mathrm{Sn}_{2} \mathrm{P}_{2}$ compound, the temperature dependence of di- 
electric susceptibility at the second order ferroelectric PT after a long term temperature stabilization in the paraelectric phase near $\mathrm{T}_{0}$ splits into two anomalies and probably there appears an intermediate IC phase. For selenium compound in the IC phase of the memory effect recording becomes more efficient at the increase of the concentration of charge carriers. The dielectric output of domain walls in the ferroelectric phase of $\mathrm{Sn}_{2} \mathrm{P}_{2} \mathrm{Se}_{6}$ also depends on the specimen conductivity [2]. At the increase of the concentration of static defects, which occurs in the solid solutions $\left(\mathrm{Pb}_{y} \mathrm{Sn}_{1-y}\right)_{2} \mathrm{P}_{2} \mathrm{Se}_{6}$ and $\mathrm{Sn}_{2} \mathrm{P}_{2}\left(\mathrm{Se}_{x} \mathrm{~S}_{1-x}\right)_{6}$, the smearing of dielectric constant temperature anomalies is observed at the $\mathrm{PT}\left(\mathrm{T}_{i}\right)$ from paraelectric phase to IC phase and at a lock-in transition $\left(\mathrm{T}_{\mathrm{c}}\right)$ from IC phase to ferroelectric phase. At the same time, both the hysteresis of the value of $\mathrm{T}_{\mathrm{c}}$ at cooling and at heating and the anomalous temperature hysteresis of the thermodynamic properties of the crystal in the IC phase are increasing [3].

It is interesting to compare the influence of static and dynamic defects on the nonequilibrium behaviour of proper ferroelectrics-semiconductors in the incommensurate and ferroelectric phases. To this end, we investigated the dielectric properties of $\mathrm{Sn}_{2} \mathrm{P}_{2} \mathrm{Se}_{6}$ crystals with different impurities and the effectiveness of the recording of a thermal memory effect in the IC phase of these crystals. The atoms $\mathrm{Pb}, \mathrm{S}$, and Mn were used as the impurities.

In case of $\mathrm{Sn}$ by $\mathrm{Pb}$ substitution the continuous solid solutions $\left(\mathrm{Pb}_{y} \mathrm{Sn}_{1-y}\right)_{2} \mathrm{P}_{2} \mathrm{Se}_{6}$ are realized. In the paraelectric phase of these crystals the atoms of metal occupy the central symmetric positions. Therefore, the $\mathrm{Pb}$ atoms in the structure of $\mathrm{Sn}_{2} \mathrm{P}_{2} \mathrm{Se}_{6}$ play the role of the impurities of "random temperature" type [4]. The two-mode concentration evolution of the Raman spectra of the low energy optical vibrations with participation of metal translations testifies to the fact that $\mathrm{Pb}$ atoms are quite "rigid" impurities [5]. This fact determines the decrease of $\mathrm{T}_{i}$ and $\mathrm{T}_{\mathrm{c}}$ till $0 \mathrm{~K}$ at $y$ increasing to 0.4 and 0.65 , correspondingly [3]. At Se by Substitution in the solid solutions $\mathrm{Sn}_{2} \mathrm{P}_{2}\left(\mathrm{Se}_{x} \mathrm{~S}_{1-x}\right)_{6}$ the one-mode concentration behaviour of the soft optic mode spectral line is observed [5]. Thus, the substitution of atoms induces deformation of the anions $\left(\mathrm{P}_{2} \mathrm{Se}_{6}\right)^{4-}$. The center of mass of these anions in the paraelectric phase coincides with the symmetry center of the elementary cell. So, atoms of $\mathrm{S}$ in the structure of $\mathrm{Sn}_{2} \mathrm{P}_{2} \mathrm{Se}_{6}$ serve as defects of a "random field" type [4]. Such defects probably are quite weak because static dipoles of acentric anion complexes obviously have little effect on the dynamics of the ferroactive cation sublattice.

According to the EPR data [6] the ions $\mathrm{Mn}^{2+}$ in crystal $\mathrm{Sn}_{2} \mathrm{P}_{2} \mathrm{Se}_{6}$ serve as impurities of impression. They occupy vacant places in the elementary cell of the crystal, which coincide with the center inversion in the paraelectric phase. The ions $\mathrm{Mn}^{2+}$ obviously appear as impurities of a "random temperature" type. It is important that introducing the $\mathrm{Mn}$ in the $\mathrm{Sn}_{2} \mathrm{P}_{2} \mathrm{Se}_{6}$ structure strongly destroys the electro-neutrality and changes the electro-conductivity of the crystals. 


\section{Experimental results}

The vapour-transport and Bridgeman methods were used for growing the crystals [3]. The crystals $\mathrm{Sn}_{2} \mathrm{P}_{2} \mathrm{Se}_{6}$ obtained by Bridgeman method had the specific resistance was $\rho \sim 5 \cdot 10^{10} \Omega \cdot \mathrm{m}$. For $\left(\mathrm{Pb}_{0.05} \mathrm{Sn}_{0.95}\right)_{2} \mathrm{P}_{2} \mathrm{Se}_{6}$ crystals obtained by vapour-transport method the specific resistance was $\rho \sim 3 \cdot 10^{10} \Omega \cdot \mathrm{m}$. Nominally clean $\mathrm{Sn}_{2} \mathrm{P}_{2} \mathrm{Se}_{6}$ crystals obtained by vapour-transport had $\rho \sim 4.2 \cdot 10^{8} \Omega \cdot \mathrm{m}$, and for $\mathrm{Sn}_{2} \mathrm{P}_{2}\left(\mathrm{~S}_{0.005} \mathrm{Se}_{0.995}\right)_{6}$ crystals with impurity of $\mathrm{Mn}$ prepared using the latter method $\rho \sim 5.5 \cdot 10^{7} \Omega \cdot \mathrm{m}$. The specimens had the dimensions about $4 \times 3 \times 1 \mathrm{~mm}^{3}$. On the normal to polar direction [100] faces, the gold was evaporated for preparing the electric contacts. The temperature dependencies of the dielectric permeability are measured by the computer controlled equipment [1]. The measurement accuracy was $0.1 \%$ for the real part $\varepsilon^{\prime}$ and $0.5 \%$ for the imaginary part $\varepsilon^{\prime \prime}$ of complex permeability. The measurements were performed at the frequency $10^{4} \mathrm{~Hz}$. The value of electric field was $0.05 \mathrm{~V} / \mathrm{cm}$. The samples were measured in conditions of darkness or at a controlled illumination. Before taking measurements the samples were being annealed in the paraelectric phase for three hours. At the thermal memory recording the temperature was stabilized to within $0.002 \mathrm{~K}$. At taking the measurements, the temperature changing rate was $0.1 \mathrm{~K} / \mathrm{min}$.

The dielectric properties of two kinds of $\mathrm{Sn}_{2} \mathrm{P}_{2} \mathrm{Se}_{6}$ crystals - Bridgeman type (B) and vapour-transport type (V) - differ noticeably. We observe the Curie Weiss like $\varepsilon^{\prime}(\mathrm{T})$ dependence in the paraelectric phase of crystal B (figure 1). In the case of crystal $\mathrm{V}$ the electric conductivity strongly effects the $\varepsilon^{\prime}(\mathrm{T})$ behaviour (figure 2). Some difference also exists for the dielectric constant temperature dependencies in the IC phase of these two samples. Big difference is observed in the ferroelectric phase. Here we can see a very strong dielectric output from the domain walls.

For B crystal, the memory effect does not occur at the temperature stabilization in darkness up till 12 hours. This effect occurs with small amplitude only at the same time temperature stabilization at white light illumination (figure 3). The memory effect is very distinctly pronounced for $\mathrm{V}$ crystal already after a two hour exposure

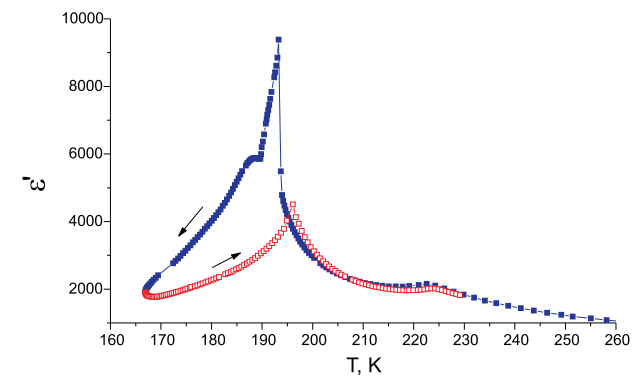

Figure 1. The temperature dependencies of the dielectric constant at cooling and heating for $\mathrm{Sn}_{2} \mathrm{P}_{2} \mathrm{Se}_{6}$ crystal with low electric conductivity (grown by Bridgeman method).

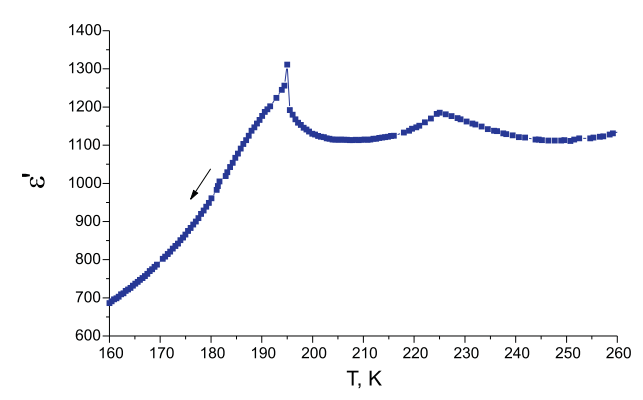

Figure 2. The temperature dependencies of the dielectric constant at cooling for $\mathrm{Sn}_{2} \mathrm{P}_{2} \mathrm{Se}_{6}$ crystal with high electric conductivity (grown by vapour-transport method). 


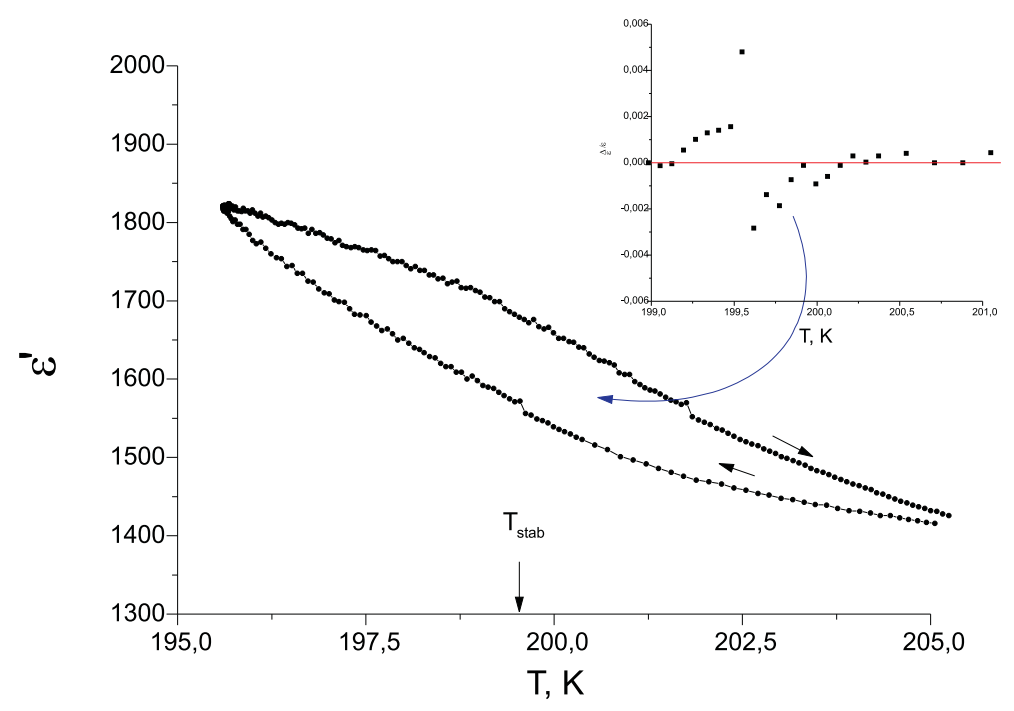

Figure 3. The thermal memory recording in the IC phase of the Bridgeman type crystal $\mathrm{Sn}_{2} \mathrm{P}_{2} \mathrm{Se}_{6}$ at white light illumination during the temperature stabilization of 12 hours. On insert: the reduced anomalous part of the dielectric constant that is related to the thermal memory effect.

in darkness (figure 4). Both the amplitude and temperature interval of the memory effect increase if we illuminate the sample with a white light at the process of temperature stabilization (figure 4a). The spectral sensitivity of memory recording has been observed as well (figure 4b).

The substitution of $\mathrm{Sn}$ by $\mathrm{Pb}$ in solid solution $\left(\mathrm{Pb}_{y} \mathrm{Sn}_{1-y}\right)_{2} \mathrm{P}_{2} \mathrm{Se}_{6}$ significantly smears the anomaly of $\varepsilon^{\prime}(T)$ at $T_{i}$, increases the hysteresis of the temperature $T_{c}$ of PT from IC phase to ferroelectric phase and decreases the dielectric output of the domain walls in the ferroelectric phase (figure 5). The influence of the cation substitutions is very strong - for example, the hysteresis of $\mathrm{T}_{\mathrm{c}}$ increases from $0.5 \mathrm{~K}$ at $y=0$ to $12 \mathrm{~K}$ at $y=0.2[8]$.
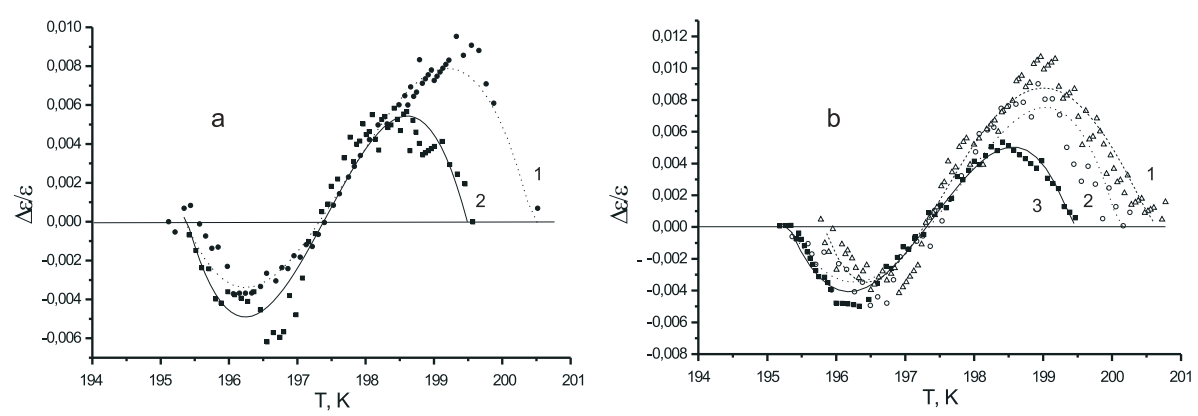

Figure 4. The reduced anomalous part of the dielectric constant that is related to the thermal memory effect in the IC phase of the vapour transport type crystal $\mathrm{Sn}_{2} \mathrm{P}_{2} \mathrm{Se}_{6}$ at the temperature stabilization time of 2 hours: a) under white light illumination (1) and in darkness (2); b) under illumination by the light with different wavelength $(1-1.000 \mu \mathrm{m}, 2-0.560 \mu \mathrm{m}, 3-0.666 \mu \mathrm{m})$. 


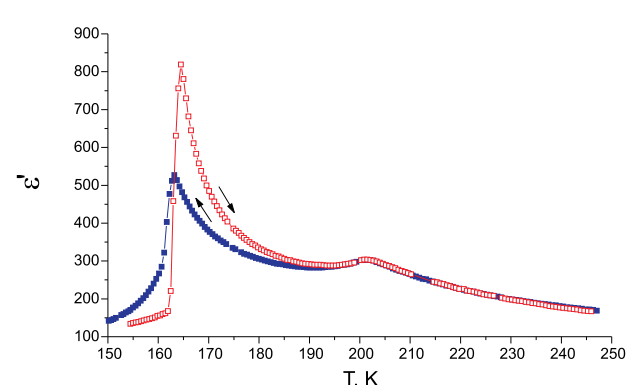

Figure 5. The temperature dependencies of the dielectric constant at cooling and heating for $\left(\mathrm{Pb}_{0.05} \mathrm{Sn}_{0.95}\right)_{2} \mathrm{P}_{2} \mathrm{Se}_{6}$ crystal.

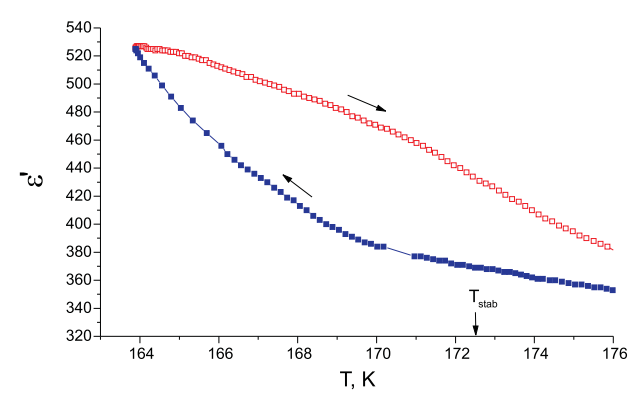

Figure 6. The result of the thermal memory recording in the IC phase of the $\left(\mathrm{Pb}_{0.05} \mathrm{Sn}_{0.95}\right)_{2} \mathrm{P}_{2} \mathrm{Se}_{6}$ crystal at white light illumination during the temperature stabilization for 5 hours.

It was found that for $\left(\mathrm{Pb}_{0.05} \mathrm{Sn}_{0.95}\right)_{2} \mathrm{P}_{2} \mathrm{Se}_{6}$ crystals at the temperature stabilization in the IC phase for 5 hours upon white light illumination of the sample, the anomalies on the temperature dependencies of $\varepsilon^{\prime}(\mathrm{T})$, which are characteristic to the memory effect recording, don't occur (figure 6). Earlier [1] it was shown that at the same conditions for the nominally clean $\mathrm{Sn}_{2} \mathrm{P}_{2} \mathrm{Se}_{6}$ crystals with similar level of a specific electrical conductivity the memory effect occurs clearly enough.

Partial substitution of Se by $\mathrm{S}$ slightly increases the anomalous hysteresis of $\varepsilon^{\prime}(\mathrm{T})$ in IC phase and hysteresis $\mathrm{T}_{\mathrm{c}}$ (from $0.5 \mathrm{~K}$ at $x=1$ to $1.5 \mathrm{~K}$ at $x=0.5$ ) [3]. Introducing the impurity atoms into the anion sublattice also decreases the dielectric output of domain walls in the ferroelectric phase. Moreover, introducing the Mn impurity into the array of $\mathrm{Sn}_{2} \mathrm{P}_{2} \mathrm{Se}_{6}$ significantly raises the electro-conductivity of specimens. Therefore, we even don't observe the anomaly at $\mathrm{T}_{i}$ on the temperature dependence of dielectric constant (figure 7). Along with this the dielectric output of domain walls in the ferroelectric phase is strongly suppressed.

In crystals $\mathrm{Sn}_{2} \mathrm{P}_{2}\left(\mathrm{~S}_{0.005} \mathrm{Se}_{0.995}\right)_{6}$ with the impurity of Mn, the "memory" develops in the strongest way. For these crystals, the illumination at the temperature of stabilization significantly refines the recording of the named effect (figure 8).

Generally, it was determined that the concentration increment $\left(\mathrm{Pb}\right.$ in $\left.\mathrm{Sn}_{2} \mathrm{P}_{2} \mathrm{Se}_{6}\right)$ of the static defects makes the recording of the memory effect impossible. At an increase of the concentration of the free charge carriers (crystals $\mathrm{Sn}_{2} \mathrm{P}_{2}\left(\mathrm{~S}_{0.005} \mathrm{Se}_{0.995}\right)_{6}$ with impurity of $\mathrm{Mn}$ ) the recording of "memory" becomes better. At the same time, the static defects smear the anomaly $\varepsilon^{\prime}(\mathrm{T})$ at $\mathrm{T}_{i}$. They significantly amplify the anomalous hysteresis and deform the anomaly of $\varepsilon^{\prime}(\mathrm{T})$ in the vicinity of $\mathrm{T}_{\mathrm{c}}$. But even at a large concentration of the static defects the lock-in $\mathrm{PT}$ at $\mathrm{T}_{\mathrm{c}}$ looks like a sharp first order transition. Upon heating the clear jump on $\varepsilon^{\prime}(\mathrm{T})$ dependence at $\mathrm{T}_{\mathrm{c}}$ is observed. The increase of the concentration of the free charge carriers decreases the dielectric output of the domain walls in the ferroelectric phase more effectively than the increase of a quantity of static defects. At a large concentration of free carriers the first order PT at $\mathrm{T}_{\mathrm{c}}$ clearly occurs on $\varepsilon^{\prime}(\mathrm{T})$ dependencies, and the anomalous hysteresis slightly increases. 


\section{Discussion of the results}

For ferroelectrics-semiconductors based on $\mathrm{Sn}_{2} \mathrm{P}_{2} \mathrm{Se}_{6}$ compound, the memory effect in the IC phase occurs due to the emerging of the density wave of charge carriers. This wave is caused by the drift of charge carriers in the nonhomogenous electric field of the spontaneous polarization wave at a long time temperature stabilization and following the localization of these carriers on the trapping levels with the energy about $0.7 \mathrm{eV}$ [1]. The theory of the memory effect caused by trapped charge carriers was developed in [9] and has been used for the investigated crystals earlier $[1,10]$. The data of this work regarding the increment of the memory effect at the increase of the concentration of charge carriers agree with the previous analysis.

We can try to qualitatively explain the disappearing of the memory effect in the $\left(\mathrm{Pb}_{y} \mathrm{Sn}_{1-y}\right)_{2} \mathrm{P}_{2} \mathrm{Se}_{6}$ series the following way. The rise of the concentration of static defects promotes the destruction of the coherent wave of the spontaneous polarization. At a large concentration of such defects one can consider even the evolution of the IC phase to "chaotic" phase or to a state of dipole glass. The

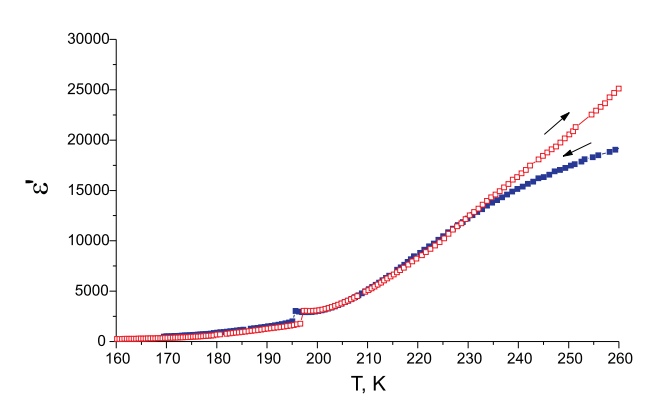

Figure 7. The temperature dependencies of the dielectric constant at cooling and heating for $\mathrm{Sn}_{2} \mathrm{P}_{2}\left(\mathrm{~S}_{0.005} \mathrm{Se}_{0.995}\right)_{6}$ crystal with the impurity of $\mathrm{Mn}$.

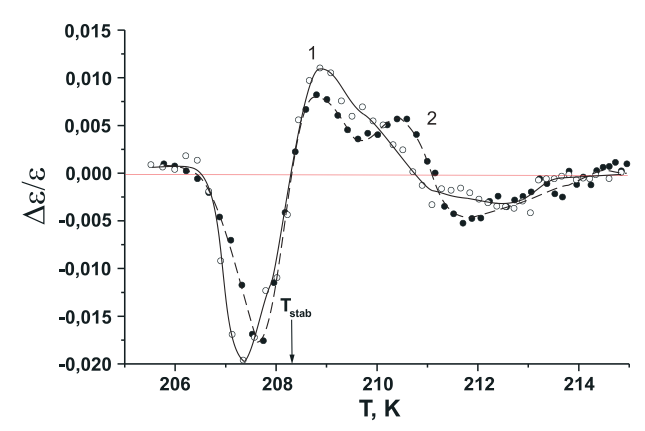

Figure 8. The reduced anomalous part of the dielectric constant that is related to the thermal memory effect in the IC phase of $\mathrm{Sn}_{2} \mathrm{P}_{2}\left(\mathrm{~S}_{0.005} \mathrm{Se}_{0.995}\right)_{6}$ crystal with the impurity of $\mathrm{Mn}$ at the temperature stabilization time of 2 hours in darkness (1) and under white light illumination (2). peculiarities of such a state are clearly seen in the solid solutions $\left(\mathrm{Pb}_{y} \mathrm{Sn}_{1-y}\right)_{2} \mathrm{P}_{2} \mathrm{Se}_{6}$ with $0.4<y<0.65$ for which the IC phase occurs in the region of $100-0 \mathrm{~K}[3,11,12]$. Simultaneous substitution of $\mathrm{Sn}$ by $\mathrm{Pb}$ and $\mathrm{Se}$ by $\mathrm{S}$ destroys the long-range order in all the temperature range of IC phase and even at a high temperature [8]. Thus, conditions for the relaxation emerging of a density wave of charge carriers disappear and we have no possibility to record the "memory".

Here at analysing the experimental data we will pay most attention to explaining the observed correlation between the efficiency of the thermal memory recording in the IC phase and to the domain structure dielectric properties in the ferroelectric phase.

Both factors, the increase of the concentration of static defects and the increase of the concentration of free charge carriers, change the concentration and the mobility 
of the domain walls in the ferroelectric phase and, as a result, their dielectric response [13] is changed.

The increase of the concentration of the static defects increases the quantity of domain walls which appear in the sample at PT from IC phase to ferroelectric phase. However, in this case, their dielectric contribution into $\varepsilon^{\prime}$ slightly decreases due to decrease in their mobility.

At the same time, the increase of the concentration of the free charge carriers promotes the compensation of a depolarizing field. By this, at PT from IC phase to ferroelectric phase, a small quantity of the domain walls appears and even the monodomain state can occur. If domain walls are charged, they can be effectively compensated by free carriers. This induces a significant decrease of the mobility of the domain walls. The piezoelectric interaction between spontaneous polarization and deformation also changes the characteristics of the domain structure.

The crystals $\mathrm{Sn}_{2} \mathrm{P}_{2} \mathrm{~S}(\mathrm{Se})_{6}$ are proper uniaxial ferroelectrics with the symmetry changing $\mathrm{P} 2_{1} / \mathrm{c}-\mathrm{Pc}$ at phase transition from paraelectric to ferroelectric phase. The $180^{\circ}$ domains with anti-collinear orientation of the spontaneous polarization vector $\overrightarrow{P_{s}}$ occur in the ferroelectric phase. Earlier, the domains in $\mathrm{Sn}_{2} \mathrm{P}_{2} \mathrm{~S}_{6}$ were observed by the optic method using the liquid crystals [14] and by the non-linear optic method based on the two-beam interaction [15]. According to the data [16] regarding the directed light scattering by the domain walls in the ferroelectric phase of $\mathrm{Sn}_{2} \mathrm{P}_{2} \mathrm{~S}_{6}$, these walls are oriented at some angle relative to the spontaneous polarization vector and, consequently, they are charged.

The analysis of the properties of domain structures in uniaxial ferroelectrics in the mean-field approximation has been performed by many authors [17-20]. Following these works we will use the thermodynamic potential density

$$
F=F_{0}+\frac{\alpha}{2} \cdot P^{2}+\frac{\beta}{4} \cdot P^{4}+\frac{\gamma}{6} \cdot P^{6}+\frac{\delta}{2}\left(\frac{\partial P}{\partial z}\right)^{2}+\ldots
$$

where $\alpha=\alpha_{T}\left(T-T_{0}\right)$ and all other coefficients are positive. From (1) after minimization we find

$$
P^{2}=P_{0}^{2} \cdot \frac{\sinh ^{2} K \cdot z}{\cosh ^{2} K \cdot z+\frac{\gamma \cdot P_{0}^{2}}{2 \cdot \gamma \cdot P_{0}^{2}+\frac{3}{2} \beta}},
$$

where

$$
K=P_{0} \cdot \sqrt{\left(\gamma \cdot P_{0}^{2}+\frac{\beta}{2}\right) / \delta}
$$

and $P_{0}$ follows from the equation $\alpha+\beta \cdot P_{0}^{2}+\gamma \cdot P_{0}^{4}=0$. The domain wall width is $r_{\mathrm{c}}=K^{-1}$. At $\gamma=0$ we find

$$
P=P_{0} \cdot \tanh \left(\frac{z}{r_{\mathrm{c}}}\right), \quad r_{\mathrm{c}}=\sqrt{\frac{2 \cdot \delta}{\alpha}}, \quad P_{0}=\sqrt{-\frac{\alpha}{\beta}} .
$$

In this case the expression for the specific surface energy of the domain wall has the following form [18]

$$
\sigma_{0}=\frac{4 \cdot \delta \cdot P_{0}^{2}}{3 \cdot r_{\mathrm{c}}}
$$


After adding to (1) the density of kinetic energy

$$
T=\frac{\rho}{2}\left(\frac{\partial u}{\partial t}\right)^{2}=\frac{m}{2} \cdot\left(\frac{\partial P}{\partial t}\right)^{2}, \quad m=\frac{\rho \cdot a^{6}}{e^{* 2}},
$$

where: $\rho$ - the density of crystal, $u$ - the shift of the ferroactive ions, $a-$ the dimension of an elementary cell, $e^{*}$ - the effective charge which is connected with the equilibrium polarization $P_{0}$ and with the equilibrium shift $u_{0}$ by the relation

$$
P_{0}=\frac{e^{*} \cdot u_{0}}{a^{3}}
$$

In this case the surface energy of the domain wall moving with velocity $\nu$ is

$$
\sigma(\nu)=\frac{\sigma_{0}}{\sqrt{1-\frac{\nu^{2}}{c^{2}}}}=m(\nu) \cdot c_{0}^{2}
$$

Here

$$
c_{0}=\sqrt{\frac{\delta}{m}}, \quad m(\nu)=\frac{\sigma_{0}}{c_{0}^{2}}\left(\sqrt{1-\frac{\nu^{2}}{c_{0}^{2}}}\right)^{-1}=m_{0} \cdot\left(1-\frac{\nu^{2}}{c_{0}^{2}}\right)^{-\frac{1}{2}}
$$

is an effective mass of a unit of the square of the domain wall. At $\nu \rightarrow 0$ we can find [18]

$$
m_{0}=\frac{\sigma_{0}}{c_{0}^{2}} \equiv \frac{4 \cdot P_{0}^{2} \cdot m}{3 \cdot r_{\mathrm{c}}}
$$

The equation of the domain wall motion in a small electric field $E$ can be written as follows:

$$
\Gamma \cdot \frac{\mathrm{d} P}{\mathrm{~d} t}=E,
$$

where $\Gamma$ is the kinetic coefficient. The mobility of the domain wall is

$$
\mu=\frac{\nu}{E}=\frac{r_{\mathrm{c}}}{P_{0} \cdot \Gamma}
$$

Taking into account the depolarization energy and the full energy of the domain walls in the specimen with the thickness $\xi$ in the polar direction $X$ we can find the equilibrium width $d$ of the domains in the ferroelectric phase of the crystal

$$
d=\sqrt{\frac{\varepsilon_{0} \cdot \xi \cdot \sigma_{0}}{k \cdot P_{0}^{2}}}
$$

Here $k=\frac{3.4}{1+\sqrt{\varepsilon_{x} \cdot \varepsilon_{z}}}, \varepsilon_{x}$ and $\varepsilon_{z}$ - the dielectric permeability of the crystal in longitudinal (polar) and transverse directions, respectively.

In the presence of the intermediate IC phase in proper uniaxial ferroelectric in the expression (1) for the thermodynamic potential density the coefficient $\delta<0$ and we should also account for the invariants

$$
\frac{g}{2}\left(\frac{\partial^{2} P}{\partial z^{2}}\right)^{2}+\frac{\lambda}{2} \cdot P^{2}\left(\frac{\partial P}{\partial z}\right)^{2}
$$


For $\mathrm{Sn}_{2} \mathrm{P}_{2} \mathrm{Se}_{6}$, two coefficients are negative $(\delta$ and $\beta)$ and all the other coefficients in (1) are positive [21]. In such a case we can find the solution for the space distribution of the spontaneous polarization in the form [18]

$$
P=P_{0} \cdot \tanh K \cdot z \text {. }
$$

Then, from (1) and (14) we obtain

$$
P_{0}^{2}=-\frac{\beta}{2 \cdot \gamma} \cdot\left(1+\sqrt{1-\sqrt{\frac{4 \cdot \gamma \cdot \alpha}{\beta^{2}}}}\right)
$$

and

$$
K^{2}=\frac{k_{i}^{2}}{8}\left[\left(1-\frac{\lambda}{2 \cdot \delta} \cdot P_{0}^{2}\right)+\left\{\left(1-\frac{\lambda \cdot P_{0}^{2}}{2 \cdot \delta}\right)^{2}-\frac{4 \cdot \alpha}{\alpha_{i}}\right\}^{0.5}\right]
$$

where

$$
k_{i}^{2}=-\frac{\delta}{2 \cdot g}, \quad \alpha_{i}=\alpha+\frac{\delta^{2}}{4 \cdot g} .
$$

Now the surface energy of the domain wall in the ferroelectric phase is $\sigma=h \cdot \frac{F_{f}}{K}$. Here $h$-some coefficient, and the energy of the ferroelectric phase

$$
F_{f}=\frac{-\beta^{3}+6 \cdot \alpha \cdot \beta \cdot \gamma-\left(\beta^{2}-4 \cdot \alpha \cdot \gamma\right)^{\frac{3}{2}}}{24 \cdot \gamma^{2}} .
$$

In the approximation $\gamma=0$ from the equations (4) and (5) we get the following temperature dependencies for the domain wall width, energy and mobility

$$
r_{\mathrm{c}} \sim\left|T-T_{0}\right|^{-\frac{1}{2}}, \quad \sigma \sim\left|T-T_{0}\right|^{\frac{3}{2}}, \quad \mu \sim\left|T-T_{0}\right|^{-1} .
$$

Near the Lifshitz point, where $\delta=0$, these dependencies have the following form

$$
\begin{gathered}
r_{\mathrm{c}}^{\mathrm{LP}}=\left(\frac{g}{\alpha}\right)^{\frac{1}{4}} \sim\left|T_{\mathrm{LP}}-T\right|^{-\frac{1}{4}}, \\
\sigma^{\mathrm{LP}} \sim \frac{g^{\frac{1}{4}} \cdot \alpha^{\frac{7}{4}}}{\mu} \sim\left|T_{\mathrm{LP}}-T\right|^{\frac{7}{4}}, \\
\mu=\frac{r_{\mathrm{c}}}{P_{0} \cdot \Gamma} \sim\left|T_{\mathrm{LP}}-T\right|^{-\frac{3}{4}} .
\end{gathered}
$$

The contribution of the domain walls into a dielectric permeability is determined by formula [17]

$$
\varepsilon=\frac{2 \cdot P_{0} \cdot \xi}{\varepsilon_{0} \cdot E \cdot d}
$$

where $\varepsilon_{0}$ is a dielectric constant, $\xi$ is a parameter of translation displacements of the domain walls. The frequency dependence of the dielectric permeability follows from the equation of motion

$$
M \cdot \frac{\mathrm{d}^{2} \xi}{\mathrm{d} t^{2}}+N \cdot \frac{\mathrm{d} \xi}{\mathrm{d} t}+\widetilde{K} \cdot \xi=2 \cdot P_{0} \cdot E
$$


where: $m_{0} \approx \frac{m \cdot P_{0}^{2}}{r_{\mathrm{c}}} \equiv M$ is the effective mass of the unit of square of the domain wall, $N \approx \frac{L \cdot P_{0}^{2}}{r_{\mathrm{c}}}$ is the dissipation coefficient. Here $L$ - the soft optic mode damping, $\widetilde{K}$ - the rigidity of the pinning of the domain walls. So, the spectrum of the domain wall real part dielectric output is

$$
\varepsilon^{\prime}=\frac{4 \cdot P_{0}^{2}}{M \cdot \varepsilon_{0} \cdot d} \cdot \frac{\left(\omega_{0}^{2}-\omega^{2}\right)}{\left(\omega_{0}^{2}-\omega^{2}\right)+\omega^{2} \cdot \tau^{2}},
$$

where

$$
\tau \cong \frac{N}{M} \quad \text { and } \quad \omega_{0}=\left(\frac{\widetilde{K}}{M}\right)^{0.5}
$$

are, consequently, the damping coefficient and the proper frequency of the domain wall vibrations. At the approximation $\tau \rightarrow 0$ and $\omega \rightarrow 0$ from (24) one can find

$$
\widetilde{K}=\frac{4 \cdot P_{0}^{2}}{\varepsilon_{0} \cdot d \cdot \varepsilon^{\prime}}
$$

In the ferroelectric phase, far from the temperature of phase transition, we can estimate the characteristics of the domain walls in $\mathrm{Sn}_{2} \mathrm{P}_{2} \mathrm{~S}_{6}$. We will use the data for $300 \mathrm{~K}$. Here, volume of the elementary cell $\mathrm{V}=4.56 \cdot 10^{-28} \mathrm{~m}^{3}, \rho=3.56 \cdot 10^{3} \mathrm{~kg} \cdot \mathrm{m}^{-3}$, $P_{0}=0.15 \mathrm{C} \cdot \mathrm{m}^{-2}, u_{0}=0.26 \cdot 10^{-10} \mathrm{~m}, \varepsilon_{x} \approx 200$ and $\varepsilon_{z} \approx 50$. The coefficients of the thermodynamic potential (1) $\quad \alpha_{T} \sim 1.6 \cdot 10^{6} \mathrm{~J} \cdot \mathrm{m} \cdot \mathrm{C}^{-1} \cdot \mathrm{K}^{-1}, \quad \beta \sim 7.4 \cdot 10^{8} \mathrm{~J} \cdot \mathrm{m}^{5} \cdot \mathrm{C}^{4}$, $\gamma \sim 3.5 \cdot 10^{10} \mathrm{~J} \cdot \mathrm{m}^{9} \cdot \mathrm{C}^{5}, \delta \sim 1.5 \cdot 10^{-10} \mathrm{~J} \cdot \mathrm{m}^{3} \cdot \mathrm{C}^{2}[21]$. According to the ultrasound data [22] $\Gamma \sim 12.8 \cdot 10^{-6} \mathrm{~J} \cdot \mathrm{m} \cdot \mathrm{s} \cdot \mathrm{C}^{-2}$.

For the listed parameters using the above shown formulas we can estimate: $e^{*} \approx 2.6 \cdot 10^{-18} \mathrm{C}, m \approx 1.1 \cdot 10^{-16} \mathrm{Kg} \cdot \mathrm{m}^{3} \cdot \mathrm{C}^{-2}, c_{0} \approx 1.2 \cdot 10^{3} \mathrm{~m} \cdot \mathrm{s}^{-1}, \sigma \approx 1.1 \cdot 10^{-3} \mathrm{~J} \cdot \mathrm{m}^{-2}$, $r_{\mathrm{c}} \approx 4.2 \cdot 10^{-9} \mathrm{~m}, d \approx 1.6 \cdot 10^{-7} \mathrm{~m}, \mu \approx 2.2 \cdot 10^{-3} \mathrm{C} \cdot \mathrm{m}^{2} \cdot \mathrm{J}^{-1} \cdot \mathrm{s}^{-1}, M \approx 7.6 \cdot 10^{-10} \mathrm{~kg} \cdot \mathrm{m}^{-2}$, $\widetilde{K} \approx 3.2 \cdot 10^{14} \mathrm{~N} \cdot \mathrm{m}^{-2}$. In this case we can estimate the frequency of the vibrations of the domain walls $\varpi_{0} \approx 10^{10} \mathrm{~Hz}$.

According to the experimental data of dielectric [23] and ultrasound [22] spectroscopy in the ferroelectric phase of the crystals $\mathrm{Sn}_{2} \mathrm{P}_{2} \mathrm{~S}_{6}$ and $\mathrm{Sn}_{2} \mathrm{P}_{2} \mathrm{Se}_{6}$ the vibrations of the domain walls have got frequencies in the interval of $10^{7}-10^{8} \mathrm{~Hz}$.

Such small values of the discussed frequencies observed here can be caused by the piezoelectric interaction between polarization and deformation in the polar phase. Such interaction increases the mass of the domain walls and, consequently, decreases the frequency of their vibrations [19]. To account for this effect we should add to (1) the energy

$$
F_{\mathrm{el}}=c_{i j k l} \cdot u_{i j} \cdot u_{k l}+q_{i j k l} \cdot u_{i j} \cdot P_{k}^{2}
$$

where: $u_{i j}$ - elastic deformations; $c_{i j k l}$ - elastic modulus; $q_{i j k l} \equiv q_{\mathrm{el}^{-}}$coefficients of electrostriction. Thus we find the next expression for the effective mass of the domain wall [19]

$$
M_{e f}=\frac{2 \cdot P_{0}^{4} \cdot l^{2} \cdot q_{\mathrm{el}}^{2}}{\varepsilon_{x}^{2} \cdot \rho \cdot c^{4} \cdot d}
$$


For the parameters listed above and for the values of sound velocity $c \approx 2.5 \cdot 10^{3} \mathrm{~m} \cdot \mathrm{s}^{-1}$, electrostriction coefficients $q_{\mathrm{el}} \approx 3.5 \cdot 10^{9} \mathrm{~J} \cdot \mathrm{m} \cdot \mathrm{C}^{-2}[21]$, the sample dimension $l \approx 2 \cdot 10^{-3} \mathrm{~m}$, using the relations (25), (26) and (28) we found the frequency of the domain wall vibrations $\varpi_{0} \approx 3.8 \cdot 10^{8} \mathrm{~Hz}$. This value coincides with the experimental data [22],[23].

According to the relations (4) the width of domain wall under the cooling decreases from $\sim 4.3 \cdot 10^{-9} \mathrm{~m}$ at $\mathrm{T}_{0}-\mathrm{T}=20 \mathrm{~K}$ to $\sim 1.3 \cdot 10^{-9} \mathrm{~m}$ at $\mathrm{T}_{0}-\mathrm{T}=100 \mathrm{~K}$. So, at temperature decreasing the width of the domain walls decreases up to the dimensions of the elementary cell of the crystal lattice. For this matter, we observe the well known effect of "freezing" of the domain walls, which appears in $\mathrm{Sn}_{2} \mathrm{P}_{2} \mathrm{~S}_{6}$ as the maximum of the dielectric losses at $\mathrm{T}_{0}-\mathrm{T} \sim 100 \mathrm{~K}$ and a decrease of the domain contribution to dielectric permeability at $\mathrm{T}_{0}-\mathrm{T}>100 \mathrm{~K}[24]$.

Earlier we have analyzed the domain structure in the ferroelectric phase of dielectric crystals. In fact $\mathrm{Sn}_{2} \mathrm{P}_{2} \mathrm{~S}(\mathrm{Se})_{6}$ crystals are ferroelectrics-semiconductors. The change of the concentration of the free charge carriers and the variation of the density of donor or acceptor impurity states can change the configuration of the domain structure. So, the dimension of domains $d$ depends on the concentration of the free carriers of the charge $n$ and also depends on the density of impurity state on the surface of the sample $N_{i}[20]$ :

$$
d=\left(\frac{2 \cdot \pi \cdot \sqrt{\pi}}{l \cdot \sqrt{\varepsilon_{0} \cdot \varepsilon_{z} \cdot \delta}}-\frac{1}{\varepsilon_{0} \cdot \varepsilon_{z} \cdot \lambda^{2}}\right)^{-\frac{1}{2}}, \quad \tilde{\lambda}^{2}=\frac{k_{\mathrm{B}} \cdot T}{4 \cdot \pi \cdot e^{2} \cdot n}
$$

and

$$
d=\pi \cdot\left(\frac{2 \cdot \pi \cdot \sqrt{\pi}}{\sqrt{\varepsilon_{0} \cdot \varepsilon_{z} \cdot \delta} \cdot l}-\frac{32 \cdot \pi \cdot N_{i} \cdot e^{2}}{\Delta E \cdot \varepsilon_{0} \cdot \varepsilon_{z} \cdot l}\right)^{-\frac{1}{2}} .
$$

From the relations (29) and (30) it follows that at the critical concentrations

$$
n^{\mathrm{cr}}=\frac{k_{\mathrm{B}} \cdot T}{4 \cdot e^{2} \cdot l} \cdot \sqrt{\frac{\pi \cdot \varepsilon_{0} \cdot \varepsilon_{z}}{\delta}}
$$

and

$$
N_{i}^{\mathrm{cr}}=\frac{\sqrt{\pi \cdot \varepsilon_{0} \cdot \varepsilon_{z}}}{16 \cdot e^{2}} \cdot \frac{\Delta E}{\sqrt{\delta}}
$$

the sample becomes monodomain $(d \rightarrow \infty)$. For $\mathrm{Sn}_{2} \mathrm{P}_{2} \mathrm{~S}_{6}$ platelet sample with the thickness $l=2 \cdot 10^{-3} \mathrm{~m}$ and using the above listed parameters and taking the energy of impurities level $\Delta E_{i} \approx 0.7 \mathrm{eV}[1]$ for temperature $330 \mathrm{~K}$ we estimate $n^{\text {cr }} \approx 6.8 \cdot 10^{19}$ $\mathrm{m}^{-3}$ and $N_{i}^{\mathrm{cr}} \approx 0.9 \cdot 10^{18} \mathrm{~m}^{-2}$.

For the crystals $\mathrm{Sn}_{2} \mathrm{P}_{2} \mathrm{Se}_{6}$ and $\mathrm{Sn}_{2} \mathrm{P}_{2} \mathrm{~S}_{6}$, the two relaxation effects (i.e., the thermal memory in the incommensurate phase of $\mathrm{Sn}_{2} \mathrm{P}_{2} \mathrm{Se}_{6}$ and the second order ferroelectric $\mathrm{PT}$ splitting after a long term temperature stabilization near $\mathrm{T}_{0}$ in the paraelectric phase of $\mathrm{Sn}_{2} \mathrm{P}_{2} \mathrm{~S}_{6}$ ) are coincidentally explained using the following set of the semiconductor parameters of these compounds: the conduction electron concentration $n \approx 10^{14}-10^{16} \mathrm{~m}^{-3}$; the attachment level concentration $N_{a} \approx 10^{24} \mathrm{~m}^{-3}$ 
[1]. From the named values of $N_{a}$ it follows the estimation of the concentration of surface impurities levels $-N_{i} \approx 10^{16} \mathrm{~m}^{-2}$.

As we can see, the values of convenient concentrations $n$ and $N_{i}$ estimated based on the experimental data, are much smaller than their critical values $n^{\text {cr }}$ and $N_{i}^{\text {cr }}$. Herein, the mean domain width is probably close to the earlier estimated value $d$. In the investigated samples the specific resistance $\rho$ changes from $5 \cdot 10^{10} \Omega \cdot \mathrm{m}$ for the crystals $\mathrm{Sn}_{2} \mathrm{P}_{2} \mathrm{Se}_{6}$ obtained by the Bridgeman method up to $5.5 \cdot 10^{7} \Omega \cdot \mathrm{m}$ for the crystals $\mathrm{Sn}_{2} \mathrm{P}_{2}\left(\mathrm{~S}_{0.005} \mathrm{Se}_{0.995}\right)_{6}$ with the impurity of $\mathrm{Mn}$ prepared by a vapourtransport method. For different samples investigated the conductivity differs by three orders. At the same time we have estimated the concentrations $n$ of the charge carriers in the conduction zone for the most conductive specimens of $\mathrm{Sn}_{2} \mathrm{P}_{2} \mathrm{Se}_{6}$. From this we can conclude that in all the investigated specimens the concentrations of charge carriers are quite smaller relative to the concentration $n^{\text {cr }}$ at which the sample becomes monodomain.

So, we can believe that the decrease of the dielectric contribution domain walls to the ferroelectric phase of $\mathrm{Sn}_{2} \mathrm{P}_{2} \mathrm{Se}_{6}$ crystals at an increase of their electric conductivity is essentially caused by the decrease of the mobility of the domain walls. The mobility decreases as the result of the charged domain wall compensation by the free charge carriers.

\section{Conclusion}

For ferroelectrics-semiconductors, taking as an example the $\mathrm{Sn}_{2} \mathrm{P}_{2} \mathrm{Se}_{6}$ crystals, we have determined the interrelation between changing of the domain structure dielectric properties in the ferroelectric phase and the efficiency of the thermal memory recording in the incommensurate phase at varying concentrations of mobile defects (charge carriers) and static defects.

The memory effect strongly depends on the concentration of the charge carriers (higher efficiency of the memory recording in the $\mathrm{Sn}_{2} \mathrm{P}_{2} \mathrm{Se}_{6}$ samples with larger electric conductivity; the improvement of this effect under illumination of the sample in the process of temperature stabilization as well as its sensitivity to the light wavelength). The dielectric response of the domain walls mobility effectively changes at the variations of the electric conductivity of the samples. These peculiarities can be explained by considering the dominant role of redistribution of the charge carriers in the field of the spontaneous polarization wave with their subsequent localization on the levels of the impurities.

The destruction of the memory effect occurs at the increase of the concentration of the static defects. In this case the anomalous temperature hysteresis of the dielectric constant in the IC phase improves, the dielectric anomalies at the phase transitions become more smear and the dielectric response of the domain walls in the ferroelectric phases becomes suppressed.

Generally, there was found the correlation between the shape of the temperature anomaly of the dielectric permeability at a lock-in transition as well as the dielectric properties of the domain structure of ferroelectric phase of $\mathrm{Sn}_{2} \mathrm{P}_{2} \mathrm{Se}_{6}$ ferroelectric- 
semiconductor on the one hand, and thermal memory effect in the incommensurate phase, on the other hand. The background of the mechanisms of these relaxation phenomena is the redistribution of the charge carriers in the inhomogeneous field of the spontaneous polarization (in the incommensurate or ferroelectric phase) and the fixation of these carriers on the centers of the impurities.

\section{Acknowledgements}

This work has been partially supported by INTAS within the project INTAS93-3230-ext.

\section{References}

1. Vysochanskii Yu. , Molnar A. // J. of Physical Studies, 1997, vol. 4, p. 535-543.

2. Maior M.M., Molnar S.B., Slivka V.Yu. // Ferroelectrics, vol. 192, p. 161-166.

3. Vysochanskii Yu.M., Gurzan M.I., Maior M.M., Motrja S.F., Perechinskii S.I., Potorij M.V., Salo L.A., Khoma M.M., Slivka V.Yu., Voroshilov Yu.V. // Sov. Phys. Solid State, 1985, vol. 27, p. 529.

4. Levanyuk A.P., Sigov A.S. Defects and Structural Phase Transitions. New York, Gordon and Breach, 1987.

5. Vysochanskii Yu.M., Slivka V.Yu. // Sov. Phys. Usp., 1992, vol. 32, p. 123.

6. Geifman I.N., Kozlova I.V., Vysochanskii Yu.M., Kofman V.Ya., Mikailo O.A. // Appl. Magn. Resonance, 1991, vol. 2, p. 435-441.

7. Maior M.M., Vysochanskii Yu.M., Slivka V.Yu., Gurzan M.I. // Fiz. Tverd. Tel., 1985, vol. 27 , p. $1560-1562$.

8. Maior M.M., Vysochanskii Yu.M., Salo L.A., Rizak V.M., Potorij M.V., Slivka V.Yu. // Fiz. Tverd. Tel., 1989, vol. 31, p. 203-208

9. Mamin R.F. // Sov. Phys. Solid State, 1991, vol. 33, p. 1473.

10. Maior M.M., Rasing Th., Eijt S.W.H., van Loosdrecht P.H.M., van Kempen H., Molnar S.B., Vysochanskii Yu.M., Motrja S.F., Slivka V.Yu. // J. Phys. C, 1994, vol. 6, p. $11211-11220$.

11. Maior M.M., Molnar S.B., Vysochanskii Yu.M., Slivka V.Yu., Rasing Th., van Loosdrecht P.H.M., van Kempen H. // Phys. Rev. B, 1995, vol. 51, p. 9325-9328.

12. Maior M.M., Wiegers S.A.J., Rasing Th., Eijt S.W.H., Penning F.C., Vysochanskii Yu.M., Motrja S.F., van Kempen H. // Ferroelectrics, 1997, vol. 202, p. 139-147.

13. Lines M., Glass A. Principles and Applications of Ferroelectrics and Related Materials. Oxford, Clarendon Press, 1987.

14. Vysochanskii Yu.M., Maior M.M., Perechinskii S.I., Tikhomirova N.A. // Sov. J. Crystallogr., 1992, vol. 37, p. 90.

15. Grabar A.A., Bercha A.I., Simchera V.Yu., Stoika I.M. // Ferroelectrics, 1997, vol. 202, p. $211-217$.

16. Grabar A.A. // Tech. Phys. Lett., 1997, vol. 23, p. 635-637.

17. Strukov B.A., Levanyuk A.P. The Physical Principles of Ferroelectric Phenomenon in Crystals. Moskow, Nauka, 1983 (in Russian).

18. Sidorkin A.S. // Ferroelectrics, 1997, vol. 191, p. 109-128.

19. Sidorkin A.S., Nesterenko L.P. // Fiz. Tverd. Tela (St. Petersburg), 1995, vol. 37, p. $3747-3752$. 
20. Sidorkin A.S., Darinskii B.M., Sigov A.S. // Phys. Solid. State, 1997, vol. 39, p. 823825.

21. Vysochanskii Yu.M., Maior M.M., Rizak V.M., Slivka V.Yu., Khoma M.M. // Sov. Phys. JETF, 1989, vol. 68, p. 782-787.

22. Samulionis V., Valevichius V., Grigas J. // Ferroelectrics, 1990, vol. 105, p. 397-402.

23. Grigas J., Kalesinskas V., Lapinskas S. // Ferroelectrics, 1988, vol. 80, p. 225-228.

24. Maior M.M., Vysochanskii Yu.M., Bovtun V.P., Poplavko Yu.M., Koperles B.M. // Fiz. Tverd. Tel., 1985, vol. 27, p. 1263-1266.

\title{
Вплив дефектів і провідності на властивості доменної структури та ефект пам'яті в сегнетоелектриках-напівпровідниках $\mathrm{Sn}_{2} \mathbf{P}_{2} \mathrm{Se}_{6}$
}

\author{
Ю.М.Височанський, А.А.Молнар, М.М.Хома, С.Ф.Мотря
}

Інститут фізики та хімії твердого тіла, Ужгородський університет, 294000 Ужгород, вул. Підгірна, 46

Отримано 6 липня 1998 р.

Для власного одновісного сегнетоелектрика $\mathrm{Sn}_{2} \mathrm{P}_{2} \mathrm{Se}_{6} 3$ неконтрольованим вмістом домішок різного типу виконані дослідження температурної залежності діелектричної проникності для встановлення впливу дефектності кристалічної структури на ефективність запису термічної “пам'яті” в неспівмірній (НС) фазі, на фазовий перехід (ФП) другого роду з параелектричної фази до НС фази при температурі ${ }_{i}$ та на ФП першого роду з НС фази до сегнетоелектричної фази при температурі ${ }_{c}$, на аномальний гістерезис температурної залежності діелектричних властивостей в НС фазі, на діелектричний вклад доменних стінок у сегнетоелектричній фазі. Статичні дефекти розмивають аномалії при ФП з параелектричної в НС фазу, збільшують аномальний гістерезис в НС фазі та гістерезис температури ${ }_{c}$ lock-in переходу, подавляють діелектричний вклад доменних стінок у сегнетофазі та руйнують ефект “пам'яті" в НС фазі. Зростання концентрації носіїв заряду також подавляє діелектричний відклик доменних стінок у сегнетоелектричній фазі, однак поряд з цим сприяє чіткішому запису "пам'яті" в НС фазі. Така тенденція погоджується з виконаними оцінками в наближенні середнього поля для характеристик доменної структури в сегнетоелектричній фазі та для ефекту “пам'яті” в НС фазі для досліджуваних сегнетоелектриків- напівпровідників.

Ключові слова: доменна структура, сегнетоелектрики-напівпровідники, вплив дефектів

PACS: $64.70 . R h, 67.70 . K b, 64.60 . F r$ 